\title{
IDENTIFICACIÓN DE LAS ZONAS DE PELIGRO ASOCIADAS A FLUJOS LAHÁRICOS GENERADOS POR LA ERUPCIÓN DEL VOLCÁN CALBUCO
}

\section{IDENTIFICATION OF THE DANGER ZONES ASSOCIATED WITH LAHARIC FLOWS GENERATED BY THE ERUPTION OF THE CALBUCO VOLCANO}

Ian Reyes Cortez*

Fabian Lizana Vásquez**

Francisco Abarca Paredes***

RESUMEN: El presente trabajo se origina en base a la utilización de diferentes procedimientos técnico-geográficos en el programa ArcGIS 10.3 con la finalidad de reconstruir escenarios de riesgo de origen volcánico generados por el Volcán Calbuco. Para ello, se modelaron diferentes formas, magnitudes e intensidades de la erupción y, por sobre todo, diversas afectaciones en las zonas urbanas que interactúan con el volcán, como también de zonas distales que se ven afectadas por otros procesos de transporte y dispersión de cenizas y de flujos. Esto se enmarca en un proyecto de planificación y análisis de los factores de riesgo asociados a los diversos procesos que actúan y se relacionan durante situaciones de erupción volcánica, en donde se desprenden variadas dinámicas asociadas a factores de composición interna del volcán y a factores externos que se convocan en torno a las condicionantes geográficas del territorio. Siendo un trabajo experimental, de laboratorio y con posible utilización en la predicción de amenazas.

Palabras clave: Erupción volcánica, población afectada, riesgo y vulnerabilidad.

* Investigador y estudiante del Magister en Geomática y Geografía Pontificia Universidad Católica de Chile, Santiago, Chile. ioreyes@uc.cl https:orcid.org/0000-000 1-6034-7696

* * Investigador y estudiante del Programa de Doctorado en Geografía Pontificia Universidad Católica de Chile, Santiago, Chile. fslizana@uc.cl https:orcid.org/0000-0002-6541-9334

***Investigador y estudiante del Programa de Doctorado en Geografía Pontificia Universidad Católica de Chile, Santiago, Chile. fabarca@uc.cl https:orcid.org/0000-0002-3676-8375 
ABSTRACT: The present work is based on the use of different technical-geographical procedures in the ArcGIS 10.3 program with the purpose of reconstructing risks scenarios of volcanic origin generated by the Calbuco Volcano. For this purpose, different forms, magnitudes and intensities of the eruption were modeled, and above all, diverse effects in the urban areas that interact with the volcano, as well as in distant areas that are affected by other processes of transport and dispersion of ashes and flows. This is part of a project to plan and analyze the risk factors associated with the various processes that act and are related during volcanic eruption situations, in which are derived various dynamics associated with factors of the internal composition of the volcano and external factors that are convened around the geographical conditions of the territory. It is an experimental, laboratory work and with possible use in hazard prediction.

Key words: Volcanic eruption, affected population, risk and vulnerability.

Recibido: 25.09.19 Aceptado: 24.02.20

\section{INTRODUCCIÓN}

La elaboración de este artículo se relaciona con el riesgo y peligro volcánico asociado al volcán Calbuco y su proceso de erupción. Esta erupción tuvo lugar el año 2015, fue una erupción volcánica ocurrida en Chile que tuvo su primer pulso eruptivo a las 17:50 hora local (UTC-3) del 22 de abril, el segundo a las 01:00 del 23 de abril y el tercero a las 13:08 del 30 de abril (Oficina Nacional de Emergencia, 2015). Este hecho causó un grave daño a la agricultura y la ganadería y por su causa se declaró el estado de excepción constitucional de zona de catástrofe, alerta roja, toque de queda, evacuación forzada de unas 9000 personas, cerca de 500 viviendas dañadas, suspensión del tránsito aéreo y daños por unos US $\$ 40000$ 000 (Ministerio de Agricultura, 2010)

Podemos mencionar diferentes factores, tanto del contexto como de los procesos, que actúan y se relacionan durante situaciones de erupción volcánica., en donde se desprenden variadas dinámicas asociadas a factores de composición interna del volcán y a factores externos que se convocan en torno a las condicionantes geográficas del territorio. Se generan con ello diferentes formas, magnitudes e intensidades de la erupción y, por sobre todo, diversas afectaciones en las zonas urbanas que interactúan con el volcán, como también de zonas distales que se ven afectadas por otros procesos de transporte y dispersión de cenizas y de flujos.

En este sentido, este artículo tiene como objetivo identificar las zonas de peligro de desastre en razón de la erupción del Volcán Calbuco, comprendiendo que una erupción se compone de varios procesos que afectan de diferente forma a las comunidades cercanas y distintas. En base a las condicionantes locales y regionales se reconocen los procesos de las zonas proximal y distal del volcán. Asimismo, el trabajo se basa en todo 
un modelo que alberga condicionantes regionales y locales para identificar las zonas de afectación, comprendiendo las dinámicas basadas en la red de drenaje del territorio y la ocupación del territorio basada en los asentamientos próximos a las zonas de afectación del modelado.

De esta forma, el trabajo consta de dos partes continuas que serán comparadas, entendiendo que ambas pueden convivir y expresar diferentes resultados que pueden ser complementarios en la demarcación de zonas de peligro generadas por los procesos laharicos y que se erigen en la función de salvaguardar la integridad de las comunidades que interactúan con los volcanes, en este caso, el volcán Calbuco ubicado en la región de los Lagos en el sur Chile.

\section{MATERIAL Y MÉTODOS}

La metodología aplicada se basa en la aplicación de modelos geoespaciales que proyectan diferentes superficies de exposición al peligro generado por los flujos Laharicos. Es por ello, que la primera parte del trabajo se basa en la aplicación de parámetros basados en el criterio GFDRR, para la cual se realizaron dos Buffer con distancias de 10 y 100 $\mathrm{km}$, confinando áreas de delimitación de afectación, incluyendo en ellas las cuencas y subcuencas en los radios de influencia. Posterior a esto, se realizó un análisis basado en la magnitud de explosividad del volcán (VEI o IEV) basándose en un radio de $10 \mathrm{~km}$, dando a conocer con ello la población afectada en el área local, generando con esto un marco de comparación con el promedio nacional.

En una segunda instancia, se elabora el cálculo de retorno del VEI a través del programa Microsoft Excel, con el cual se especifica de forma gráfica la historia de las magnitudes del volcán, estudiado entre los años 1792 y 1972. Posteriormente, se realizó un geo procesamiento en base a la herramienta de Arcgis 10.3 LaharZ con la cual se logró modelar un flujo laharico en torno a un punto de control basando su escorrentía en torno a una cuenca próxima a la estructura del volcán, representando diferentes volúmenes del flujo en diversas secciones del caudal detrítico, obtenido con ello una cartografía.

Se finaliza el estudio realizando una cartografía de peligro volcánico en base a los resultados del modelamiento de LaharZ, para con ello estimar, en base a datos censales del lugar, una estimación de la población y viviendas afectadas por el flujo laharico.

\section{RESULTADOS}

El criterio GFDRR "Global Facility for Disaster Reduction and Recovery of the World Bank" estima el nivel de peligro, el nivel de incerteza según la disponibilidad de información y el índice de exposición de la población. El riesgo de cada volcán se estima de la combinación del peligro y la exposición en un área espacial determinada. (Aguilera, 2016)

En este modelo se utiliza una serie de variables asociadas tanto a las condiciones propias del volcán como a sus productos, es decir, a los procesos que se generan producto de la erupción, destacando, además, su frecuencia e intensidad. Es por ello que se desglosan 8 factores, que son la base de la metodología mencionada: 


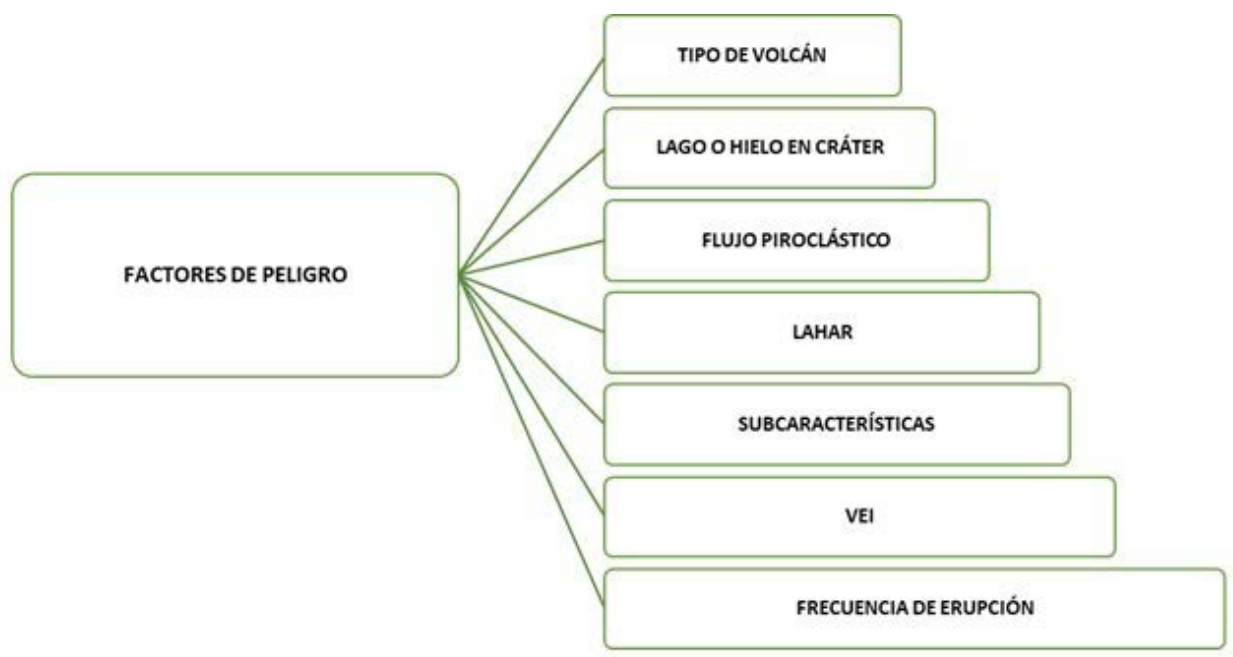

Figura 1. Factores que componen el modelo GFDRR

Fuente: Factores de base del modelo de la universidad de Bristol extraído de Aguilera, (2016).

En este sentido, para la obtención de un área de afectación de realizaron dos Buffer mediante la utilización de la herramienta "geoprocessing" del programa Arcgis 10.3, articulando dos áreas de delimitación a 10 $\mathrm{km}$ y $100 \mathrm{~km}$ de radio desde el centroide del volcán.

En segunda instancia, se aplicó el procedimiento de delimitación de cuencas hidrográficas basados en la herramienta Hidrology del mismo programa, generando con ello la diferenciación de cuencas en torno a ambas zonas de buffer, visualizando las áreas de las cuencas que están afectas al proceso laharico generado por una erupción del volcán.

\section{VEI IVOLCANO POPULATION ÍNDEX)}

Este índice posibilita poder ver la distancia y la afectación entre los diferentes radios, que

\begin{tabular}{|c|c|}
\hline Distancia KM & Población Afectada \\
\hline $5 \mathbf{k m}$ & 70 \\
\hline $10 \mathrm{~km}$ & 871 \\
\hline $30 \mathrm{~km}$ & 32.265 \\
\hline $100 \mathrm{~km}$ & 575.233 \\
\hline
\end{tabular}

Tabla. 1 Tabla de distancia y afectación según áreas. Fuente: en base a la información recogida de Smithsonian Institution. tienen como correspondencia delimitar las zonas que podrían ser afectadas por la posible erupción del volcán Calbuco. Por tanto, el VEl, permite establecer esas áreas que posibilitan controlar y gestionar adecuadamente el riesgo ante una posible erupción volcánica.

En este sentido, la aplicación de esta técnica facilita una adecuada zonificación, pudiendo identificar las poblaciones afectadas y zonas en las cuales los elementos laháricos generarán sus procesos se escurrimiento superficial.

\section{PERIODOS DE RETORNO}

Según el Gráfico 1, los periodos de retorno del volcán Calbuco serán de 29 años para episodios VEl 2, 45 años para episodios VEl 3 y 79 años para episodios VEl 4. Además, nos posibilita identificar las recurrencias en los episodios de erupción volcánico y a su vez, identificar dentro de parámetros específicos, como lo son los niveles de peligrosidad, densidad de población e identificación de las diversas áreas.

En este sentido, el Índice VEl permite decisivamente poder establecer las magnitudes y recurrencias en la erupción del volcán Calbuco y los niveles de peligrosidad que se activan en los diferentes procesos históricos de erupción volcánico. 


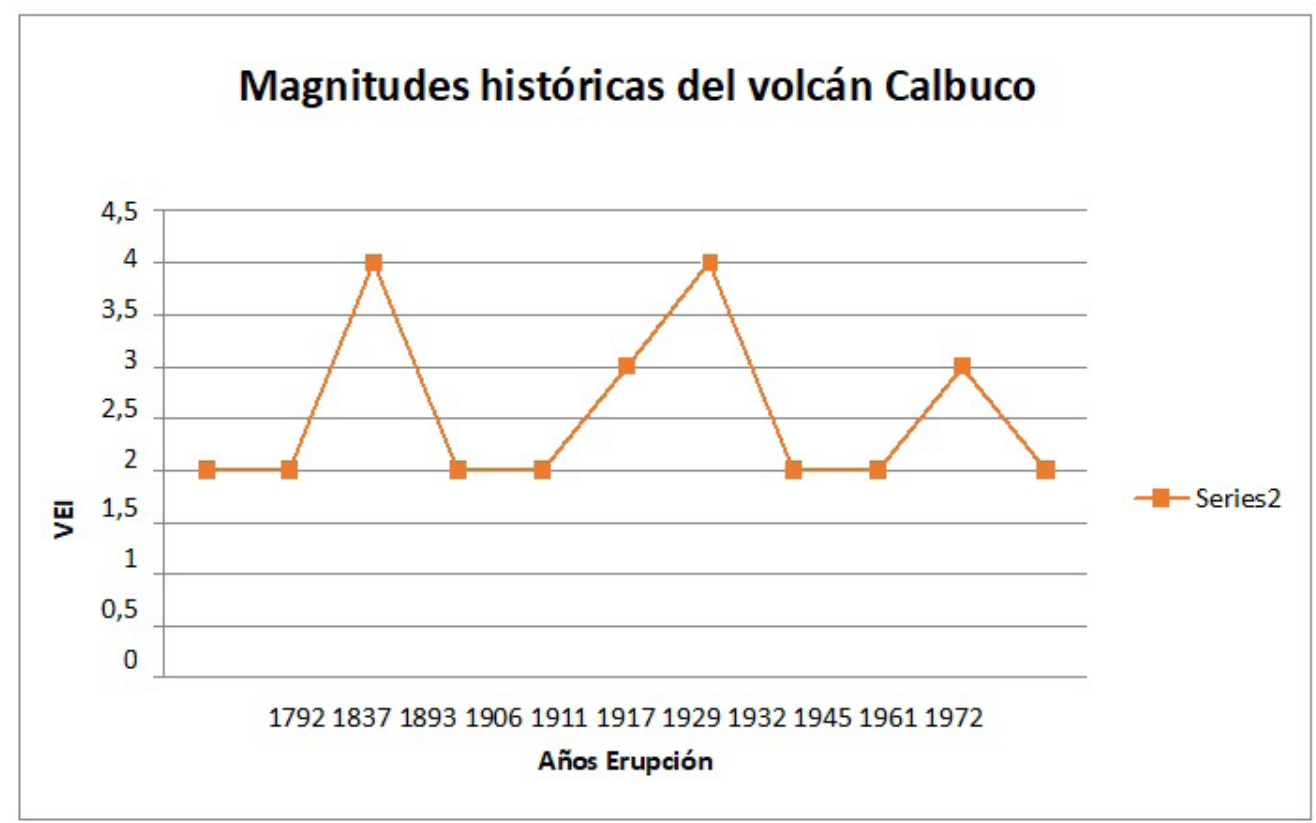

Gráfico 1. Magnitudes históricas del volcán Calbuco (1792-1972).

Zonas Censales de Cuenca Afectadas por Proceso Laharico.

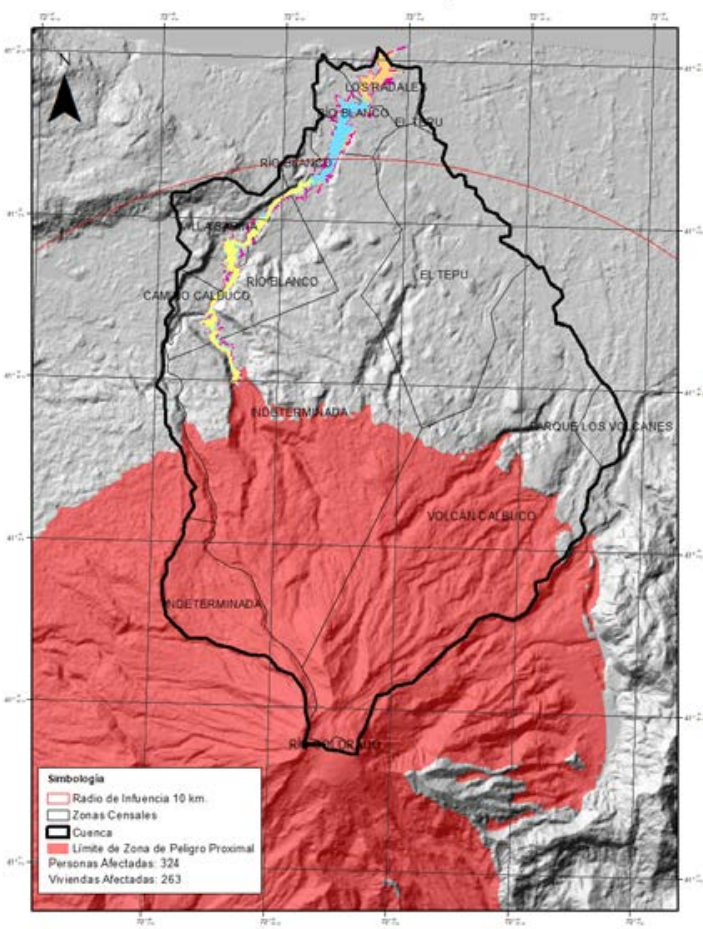

Figura 2. Alta Peligrosidad.

Fuente: Elaboración propia, en base a representación espacial en ARCGIS 10.
Zonas Censales Afectadas por Proceso Eruptivo Radio $5 \mathrm{Km}$.

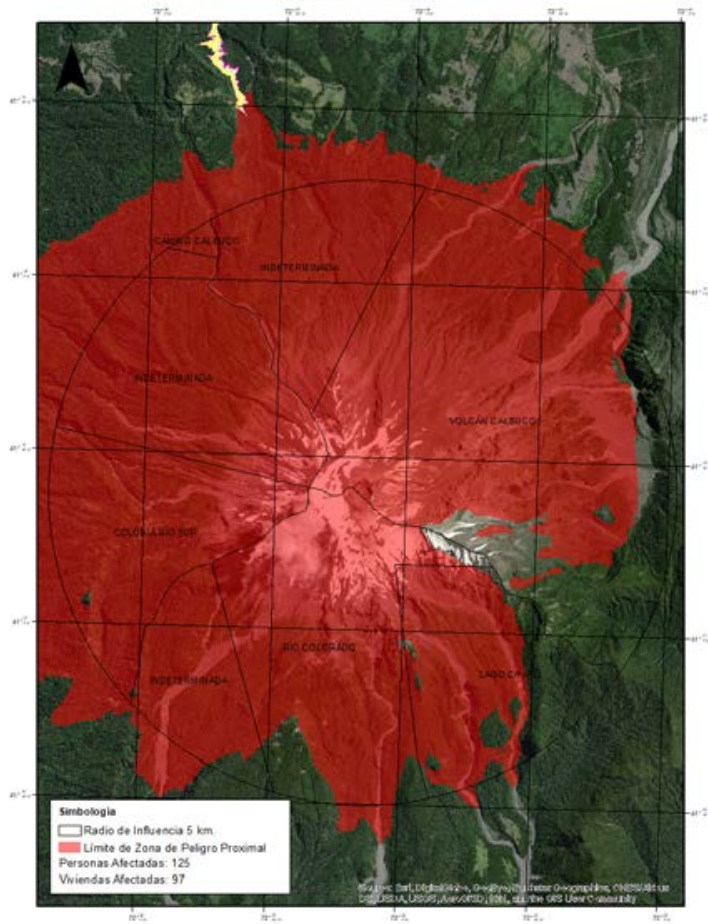

Figura 3. Alta Peligrosidad.

Fuente: Elaboración propia en base a representación espacial en ARCGIS 10 


\section{Zonas Censales Afectadas por Proceso Eruptivo y Laharico. Radio $100 \mathrm{Km}$.}

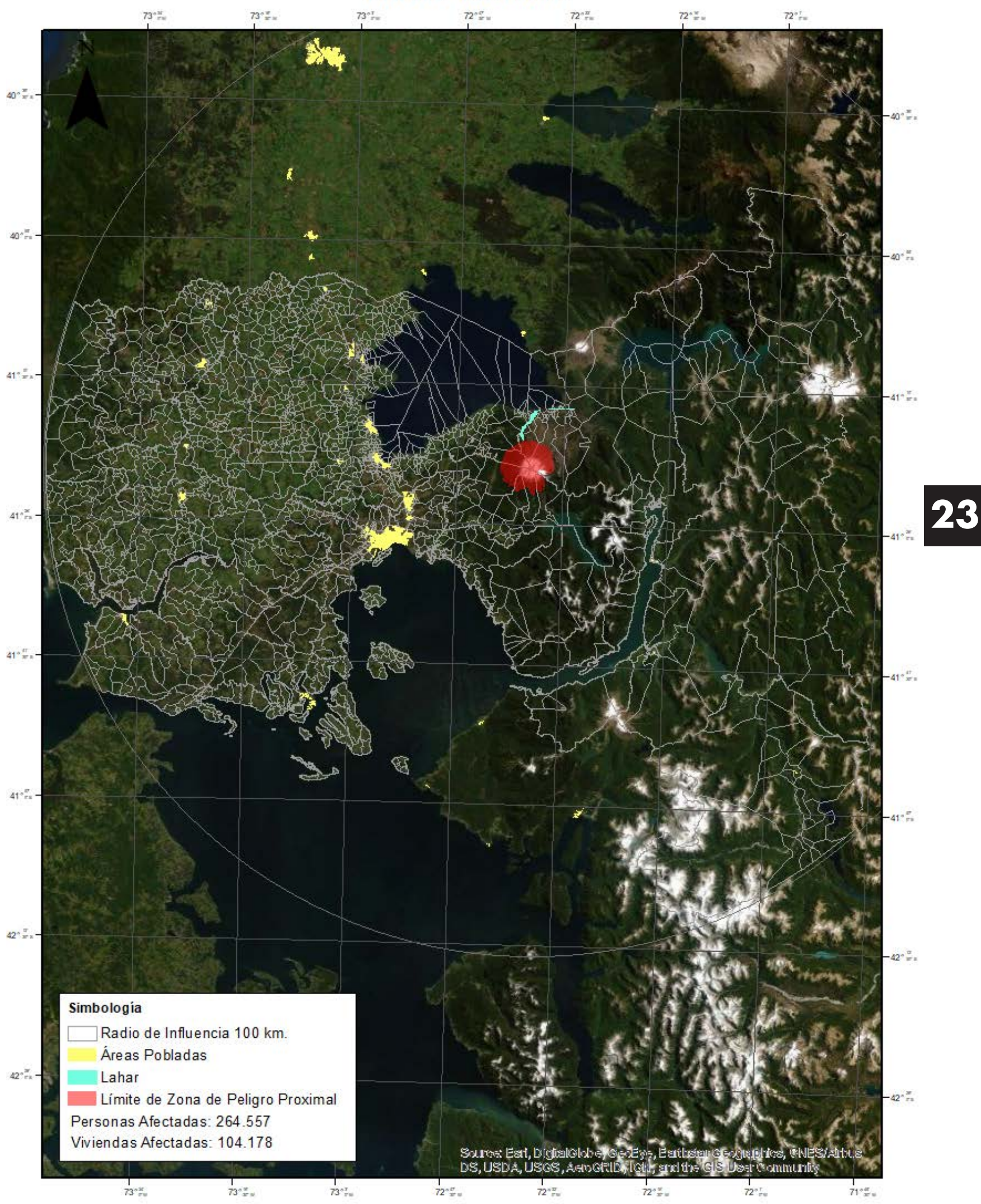

Figura 4. Media Peligrosidad

Fuente: Elaboración propia en base a representación espacial en ARCGIS 10. 


\section{Zonas Censales Afectadas por Proceso Eruptivo y Laharico.} Radio $30 \mathrm{Km}$.

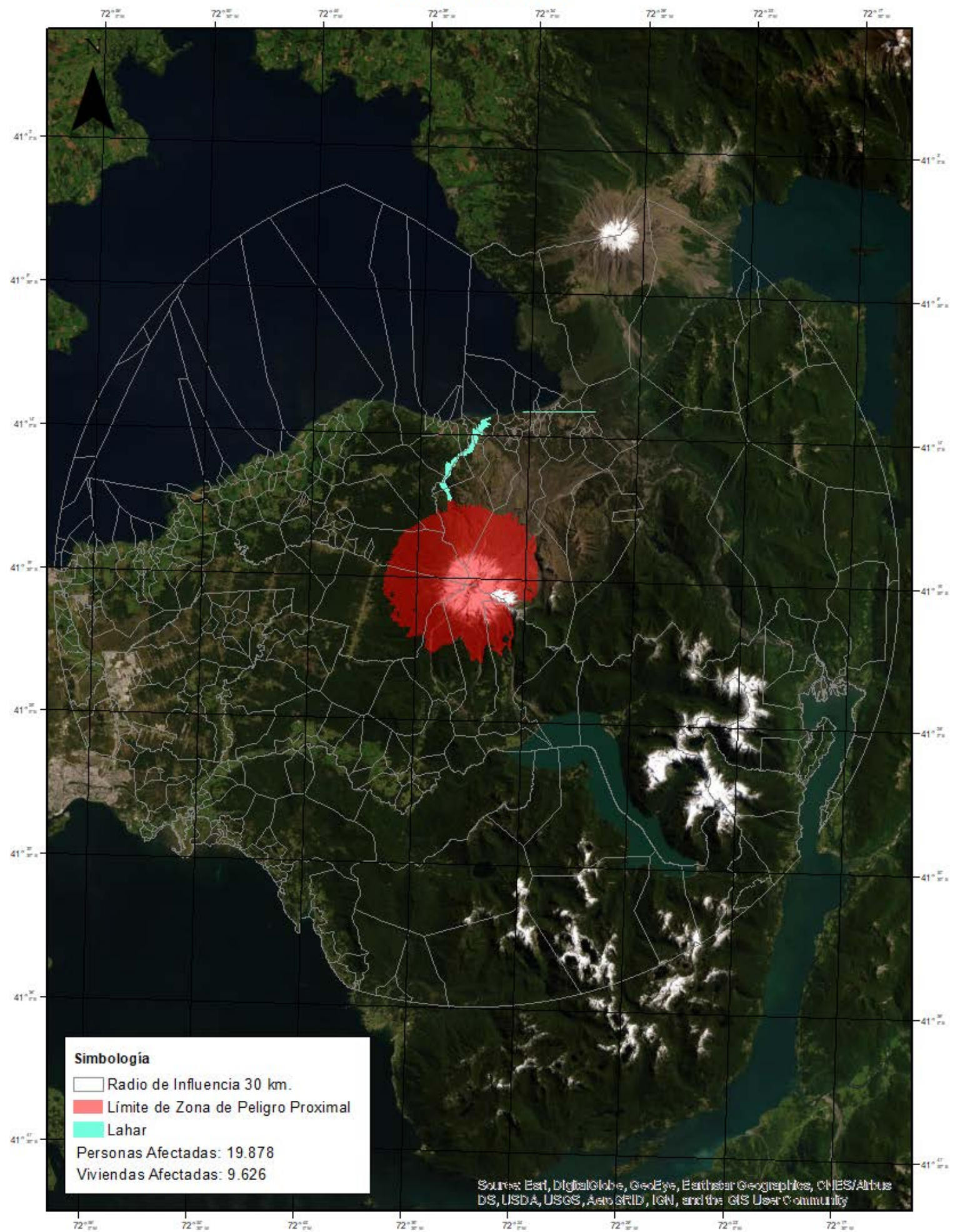




\section{CONCLUSIONES}

Según los datos aquí presentados el volcán Calbuco representa un peligro para las zonas estudiadas, teniendo principalmente peligros asociados a episodios eruptivos, pudiendo existir caída de piroclastos, corriente de lavas, flujos piroclásticos y explosión de domos calientes. Para este trabajo se observó que también uno de sus peligros que es la formación de lahares fríos o calientes, siendo este proceso un peligro inminente para las personas que habitan los sectores cercanos al volcán, a su vez existen peligros en distintas escalas según su magnitud.

Su peligrosidad dependerá del proceso que ocurra y su intensidad, para los VEI 2, 3 y 4 los procesos de lahar afectarían hasta aproximadamente los $20 \mathrm{~km}$ en la zona norte del volcán, puesto que se encontraría con el lago después de estos kilómetros.

Los mapas de peligrosidad se explican también dependiendo de su magnitud y proceso volcánico, teniendo que para $5 \mathrm{~km}$ existirá un alto peligro, pero las personas y viviendas que se verían afectadas serian alrededor de 125 personas y 97 viviendas para todos los procesos que puedan ocurrir dentro de este radio. Para el caso de 10 kilómetros también existe una alta peligrosidad, dada para todos los procesos volcánicos, y pudiendo verse afectadas 324 personas y 263 viviendas, en este caso los procesos laharicos serían de una alta peligrosidad. Para el caso de los 30 km la peligrosidad baja a media para los lahares, pero para otro tipo de peligros, como de flujos piroclastos, las viviendas afectadas serian 19.878 y 9.626 y para el caso de $100 \mathrm{~km}$ se vería afectada gran parte de la Región de los Lagos de población rural y urbana y se verían afectadas 264.557 personas y 104.176 viviendas para procesos volcánicos complejos de $V E I>$ a 4.

Cabe mencionar, que la peligrosidad dependerá del fenómeno estudiado, en este caso la peligrosidad se basa en los lahares que afectarían aproximadamente hasta los 15 km según el lahar presentado en las figuras. Toda la información de personas y vivienda se basa en el censo 2017. De su actividad registrada durante estos últimos siglos, el volcán Calbuco ha registrado 12 episodios eruptivos siendo gran parte de estos episodios de magnitud VEI 2 con un total de 7 episodios, 2 episodios de VEI 3 y 3 episodios VEl 4 contando el del año 2015, si bien no registra un gran número de episodios, sí representa un peligro para las zonas cercanas a este volcán. Por lo tanto, poder generar un modelo predictivo en base a sistemas de información geográfica que permita visualizar un posible lahar y establecer zonas de resguardo e impacto, posibilita una acción rápida para las autoridades del sector, siendo una herramienta fundamental en la generación de cartografías de peligro y zonas de afectación a procesos eruptivos complejos que pueden darse en el futuro por el volcán Calbuco.

\section{AGRADECIMIENTOS}

A Luis Lara e Iván Cerda, profesor y ayudante de la Cátedra de Peligro y Riesgo Volcánico del Programa de Magister en Geografía y Geomática del instituto de Geografía de la Pontificia Universidad Católica de Chile. Como también a los docentes de la Escuela de Geografía de la Universidad Academia de Humanismo Cristiano Marcelo Garrido y Voltaire Alvarado por su apoyo y guía.

\section{REFERENCIAS BIBLOGRÁFICAS}

Aguilera Sáez, D. M. (2016). Riesgo volcánico a escala nacional/regional: estudio comparado de variantes metodológicas, para su evaluación y adaptación al contexto volcánico de Chile. Tesis, Universidad de Chile, 225 p. Recuperado de http://repositorio. uchile.cl/handle/2250/139774

Astudillo, V., Bertin, L., Bertin, D. (2015). Características texturales y composicionales de la tefra del ciclo eruptivo de abril-mayo de 2015 del volcán Calbuco. Actas del IV Congreso Geológico Chileno, 186-189. 
González-Ferran, O. (1994). Volcanes de Segura Acevedo, A. (2016). Erupción Chile. Instituto Geográfico Militar, Santiago, subpliniana de abril de 2015 del volcán 640. Calbuco, Andes del Sur: génesis, dinámica y parámetros físicos de la columna Loughlin, S., Vye-Brown, C., Sparks, R.S. eruptiva y depósitos piroclásticos de caída J., Brown, S.K., Jenkins, S.F., (eds.) (2015). asociados. Tesis, Universidad de Chile, 99 p. Global Volcanic Hazards and Risk, Cambridge Recuperado de http://repositorio.uchile.cl/ University Press, 74. handle/2250/142799 